\title{
Functional specifications for in-stope support based on seismic and rockburst observations in South African mines
}

\author{
R.J. Durrheim CSIR Centre for Mining Innovation; and University of the Witwatersrand, South Africa
}

\begin{abstract}
Rockbursts pose a significant risk to workers in deep gold and platinum mines in South Africa. In-stope support systems are one of the measures used to mitigate the risk. Over the last two decades several new technologies have been introduced, such as prestressed elongates, roofbolts and nets. However, seismic theory and observations present several characteristics of seismically-induced ground motion that are not taken explicitly into account in the functional specifications for support design, i.e. multi-cyclic shaking, shear motion between hanging- and footwall, transient tensile forces, and structural resonances. Investigations of rockburst damage were reviewed to evaluate the significance of these phenomena. Similar phenomena affect surface structures exposed to earthquake-induced shaking, and earthquake engineers have developed a range of solutions to mitigate damage. These solutions are reviewed to evaluate whether the principles of earthquake-resistant design can be adapted to the underground environment. Finally, functional specifications for rockburst-resistant in-stope support are proposed.
\end{abstract}

\section{Introduction}

The gold-bearing conglomerates of the Witwatersrand Basin and platinum-bearing pyroxenites of the Bushveld Complex vary in thickness from a few centimetres to several metres, and extend for many kilometres along strike and down dip. Mining is approaching depths of 4 and $2.5 \mathrm{~km}$ in the Far West Rand goldfield and western limb of the Bushveld Complex, respectively. The tabular geometry, shallow dip, and strong, brittle and abrasive rock make the mechanisation of rock-breaking operations difficult. Typically stoping crews use handheld rockdrills to drill short $(1.1 \mathrm{~m})$ blast holes in panels that are about $1.2 \mathrm{~m}$ high and $30 \mathrm{~m}$ long (Vieira et al., 2001). The ore is removed using either scrapers or water jets, the hangingwall is made safe by barring, and support is installed in the face area. In contrast to many other hard rock mining methods, miners actually work inside the stope, which is a particularly demanding environment as it is constantly changing and subject to high mining-induced stresses.

Rockbursts pose a significant risk to workers in deep gold and platinum mines in South Africa. Rock reinforcement and support systems are among the measures used to mitigate the risk. Stacey (2011) argues that we have a profound lack of understanding of the behaviour of the rock mass during a seismic event, as well as the action and interaction of support elements. Hence we know neither the demand imposed on support or the performance capacity of support systems under dynamic loading, resulting in design indeterminacy. Stacey $(2009,2011)$ advocates a conservative specification approach that guarantees that the containment support and the elements that connect it to the retainment support do not fail, but successfully transfer the dynamic loading into the rockbolts. Stacey's analysis focuses on tunnel support, while this study focuses on in-stope support.

Over the last two decades, new types of prestressed yielding props and packs, in-stope roofbolts and nets have been introduced. However, the risk posed by rockbursts has not been eliminated, and efforts to improve the effectiveness of support systems continue. A first attempt to apply the techniques used by earthquake engineers to the design of rockburst-resistant excavations was made by Durrheim et al. (1998a). The work was extended by Hagan et al. (1999), Milev et al. (2002) and Cichowicz et al. (1999). However, none of the recommendations were implemented. In 2010, Gold Fields Ltd commissioned a 
review of current in-stope support elements and systems, and an investigation of the scope to improve support technologies by applying earthquake engineering concepts. Here we report on the findings.

\section{$2 \quad$ Earthquake and rockburst engineering principles}

Earthquake engineering is the discipline that seeks to limit the risk posed by earthquakes to socio-economically acceptable levels (Bozorgnia and Bertero, 2004). Firstly, the seismic loading that the structure is likely to bear is estimated. The location, size and recurrence times of past earthquakes are analysed in order to assess the seismic hazard. In order to estimate the expected intensity of shaking at the site of interest (typically expressed in terms of the peak particle velocity (PPV) and peak particle acceleration (PPA) that has a given probability of being exceeded, say $10 \%$, in a given time period, say 50 years), it is necessary to take the seismic attenuation along the propagation path into account, as well as any local site effects that may amplify the ground motion, e.g. resonance.

The second step is the design, construction or retrofitting of structures to ensure that they perform to expectation when exposed to earthquake shaking. The likely performance of the structure is assessed through forensic studies of earthquake damage; experimental evaluations, typically done by observing the performance of a (scaled) model on a shake-table that simulates actual earth shaking (Figure 1a); or by numerical modelling. Earthquake engineers have developed a range of design guidelines and technical solutions to limit the damage to structures. For example, the footprint and height of the structure are chosen to avoid resonance frequencies. The wave energy within the structure can be dissipated by properly engineered dampers; dispersed between a wider range of frequencies; or the resonant portions absorbed by mass dampers. One of the challenges of earthquake engineering is to deal with the considerable uncertainties that exist in estimates of seismic loading and predictions of structural performance.

Rock engineers and mine seismologists working in seismically-active mines have similar objectives to earthquake engineers, but their technology has not reached the same level of maturity. Mine-wide seismic networks provide information on the location, size and recurrence times of seismic events. However, only a limited number of studies of the intensity of shaking of the excavation walls have been carried out. These are summarised in Section 3. A range of rock support and reinforcement elements and systems are used to reinforce the rock mass and absorb seismic energy. Essentially two design criteria are applied: (i) the support resistance, based on the dimensions of a block that should be carried subject to gravitational loading; and (ii) the energy absorption, based on the block dimensions and the PPV. A range of prestressed energy-absorbing elements have been developed, including packs, props and tendons. A PPV of $3 \mathrm{~m} / \mathrm{s}$ has been used as a design criterion for rockburst-resistant support in gold mines since the 1980s, while a value of $1 \mathrm{~m} / \mathrm{s}$ has been adopted for platinum mines. The capacity of support elements is typically evaluated by drop tests (Figures 1(b) and 1(c)), and, in a few instances, by in situ controlled explosions (Milev et al., 2001; Heal and Potvin, 2007). These tests measure the impulse response of support elements or systems, which differs considerably from the dynamic loading imposed on a fractured rock mass by a seismic event. In situ observations of support performance following rockbursts are also made. Attempts are also made to simulate ground motion numerically. 

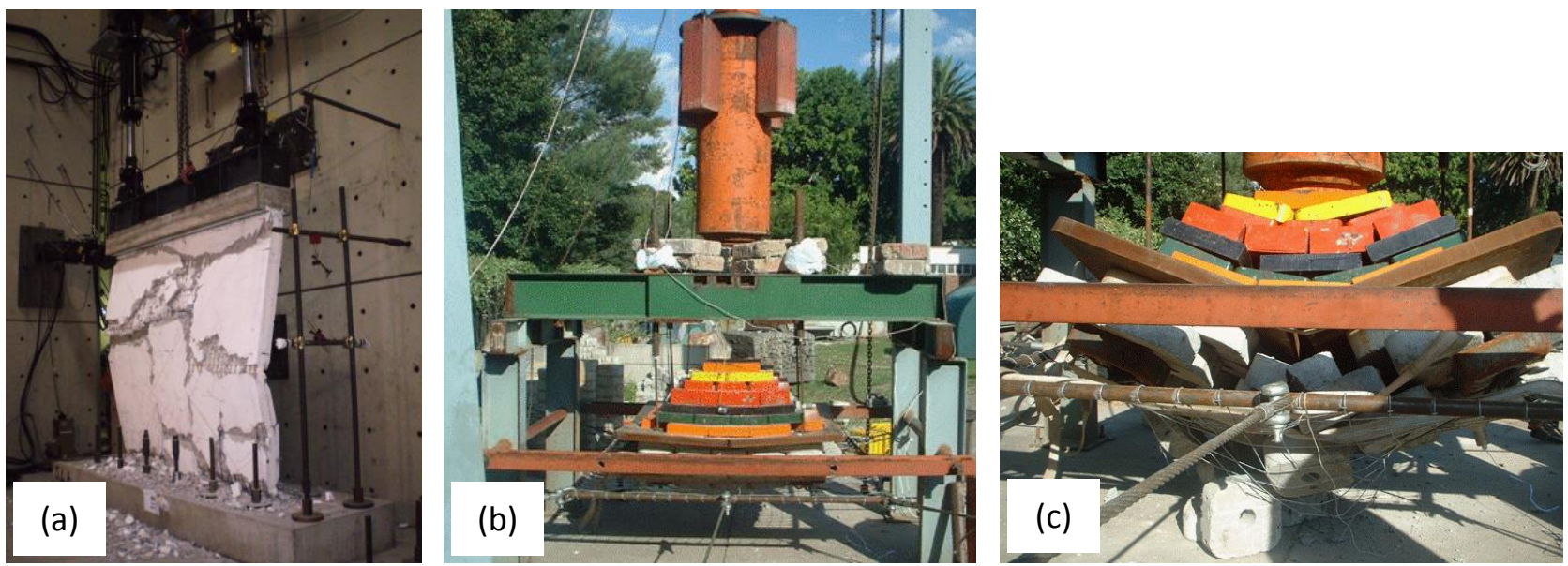

Figure 1 Dynamic testing of (a) reinforced concrete wall using hydraulic actuators capable of simulating earthquake motion; (b) and (c) tunnel support elements by means of a weight drop

A series of studies of the seismically-induced ground motion in stopes was conducted under the auspices of the South African Mine Health and Safety Council (MHSC) between 1995 and 2005. We briefly review the main findings.

\section{1 Hangingwall structure}

The rock mass comprising the hangingwall of stopes in deep mines is usually intersected by numerous discontinuities (Figure 2, after Jager and Ryder, 1999). These discontinuities can be divided into two main categories: (i) pre-existing joints and parting planes (e.g. bedding planes), whose cohesion is often destroyed by mining-induced slip displacements; and (ii) mining-induced fractures caused by the large stress concentrations around stopes, especially in abutments, remnants and pillars. Extension fractures are formed immediately in front of the face. Shear fractures are formed up to $10 \mathrm{~m}$ ahead of the face and extend as much as $30 \mathrm{~m}$ from the stope horizon. One positive aspect of fracturing sub-perpendicular to the stope is that it causes the rock to dilate, thereby generating horizontal stresses that help to clamp and strengthen the fractured hangingwall beam.

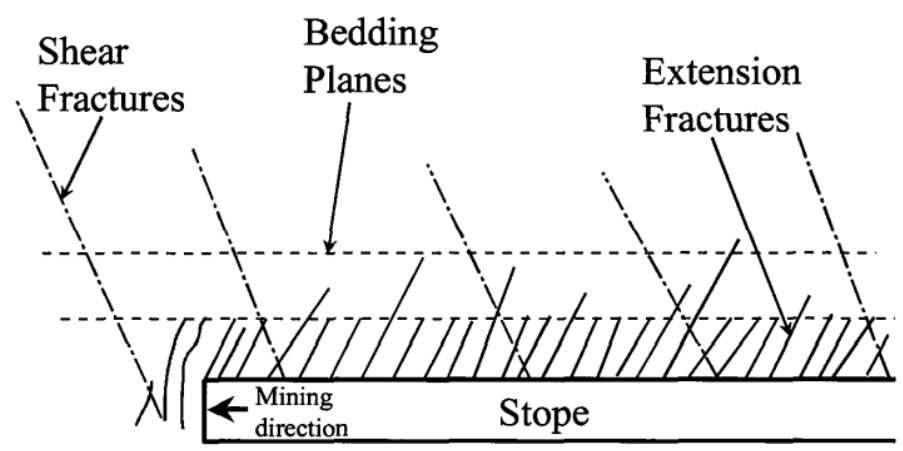

Figure 2 Diagram showing main discontinuities in the hangingwall of a deep tabular stope (after Jager and Ryder, 1999)

The discontinuities fragment the rock mass surrounding the stope into numerous blocks and slabs. A block may become unstable and fall out as the rock mass creeps, the hangingwall sags, cohesion along fracture planes is destroyed, and friction is overcome by gravity. Blocks may also be ejected by the kinetic force supplied by an elastic wave generated by a seismic event. Local support elements (props, packs, elongates, bolts, nets, thin spray-on liners, etc.) are used to hold these blocks in place and prevent the hangingwall from unravelling. 


\subsection{Investigation of the site and structural response to seismic events}

Durrheim et al. (1998a) and Hagan et al. (1999) sought to investigate whether mining excavations (the 'structure') and the envelope of fractured rock reinforced by support elements (the 'site') affect seismically-induced ground motion, and if so, if there is any potential to adapt earthquake engineering solutions to damp the resonance and limit damage. Observations were made at a number of deep mines using both passive and active sources: mining-related seismic events were monitored at Blyvooruitzicht, Vaal Reefs, TauTona mine; face-parallel preconditioning blasts were monitored at Blyvooruitzicht Mine; and a rockburst was simulated at Driefontein Mine.

\subsubsection{Comparison of ground motion on the skin of a tunnel with that in solid rock}

It was found that the ground motion (PPV) on the skin of the excavation was amplified (by 4- to 10-fold) compared to the motion in solid rock at a similar distance from the source (Figure 3, after Durrheim et al., 1996). This was not entirely surprising as a doubling of amplitude is expected at a free surface. Furthermore, it was known that the seismic velocity of the fractured rock surrounding the excavation is reduced owing to the intense fracturing. This contrast in velocity helps to 'trap' seismic energy as the low velocity surface layer enhances the formation of surface waves such as Rayleigh and Love waves. Lastly, the fractured and bulked rock is less dense, and velocity of ground motion would be expected to increase to conserve energy (Linkov and Durrheim, 1998). The measured amplification on the skin of the tunnel was successfully simulated by the damped oscillator model commonly used by earthquake engineers to simulate structures such as buildings and bridges (Cichowicz et al., 1999). However, it must be noted that the events studied were relatively small $(\mathrm{M}<2)$, and it is unlikely that the extreme levels of amplification would be generated by the longer wavelength motions produced by bigger events.

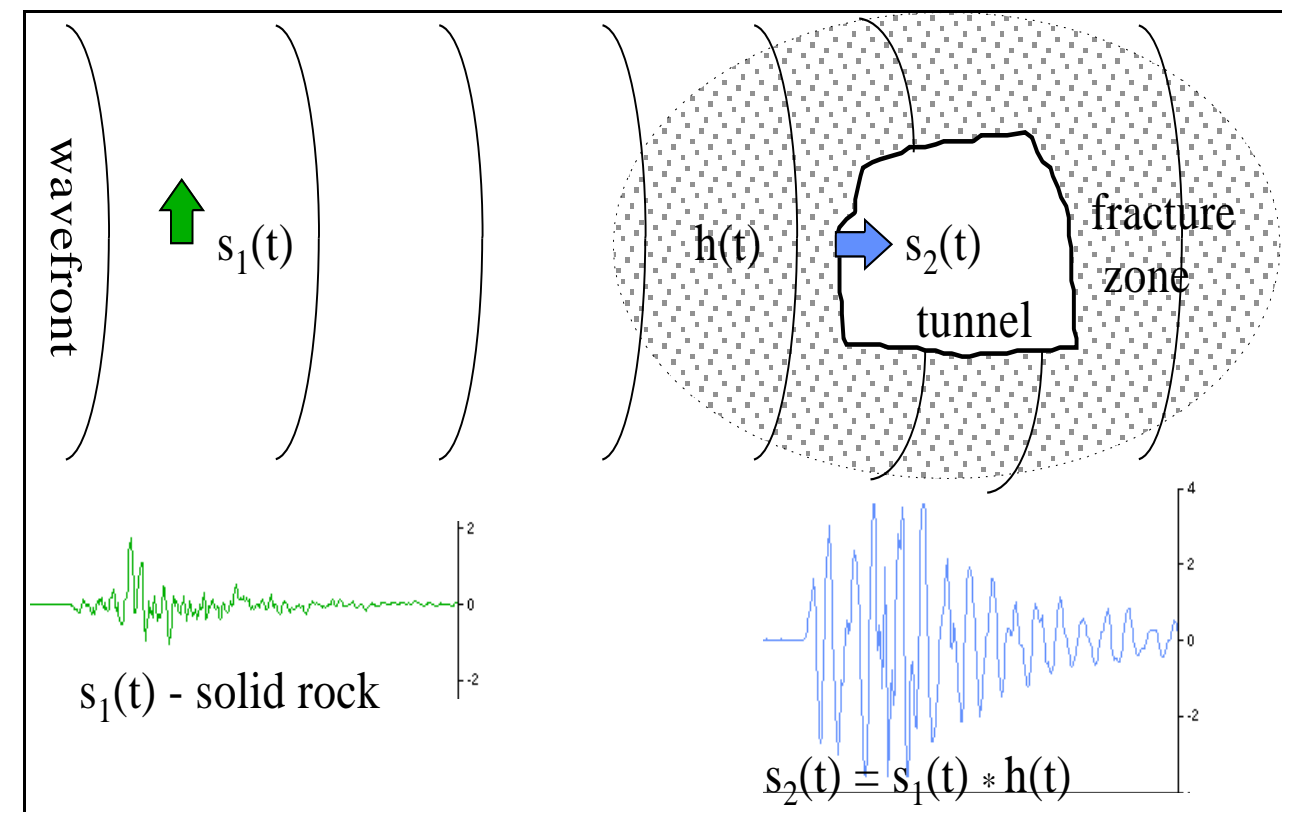

Figure 3 Diagram with actual seismograms recorded $10 \mathrm{~m}$ from the tunnel sidewall and on the sidewall (after Durrheim et al., 1996). The vertical axis is in $\mathrm{mm} / \mathrm{s}$ and the seismograms about $70 \mathrm{msec}$ in duration

\subsubsection{Effect of support units and the motion of the hangingwal/}

The motions of sensors attached to the hangingwall were compared, e.g. one sensor adjacent to a support element (e.g. pack) and another midway between the in-stope support units. It was found that the modal frequencies and damping coefficients changed with time on a scale of weeks, probably attributable to gradual changes in the mechanical properties of rock mass. There was often a significant difference in the phase of ground motion induced by the same seismic event between sensors less than $2 \mathrm{~m}$ apart, indicating non-elastic behaviour, probably the result of co-seismic slip on discontinuities. 


\subsection{Comparison of the motion of the hanging-and footwall}

The motion of the hanging- and footwall was generally incoherent, i.e. there were unsystematic differences in amplitude and phase. It could not be modelled using the damped oscillator model.

\section{2.430 array}

The 3D array at TauTona Mine comprised a $3 \times 3 \mathrm{~m}$ array of five vertical-component geophones attached to the hangingwall, a vertical array of four three-component geophones in a $6.5 \mathrm{~m}$ long borehole drilled in the hangingwall, and two vertical-component geophones attached to the footwall. Several important observations were made:

1. The vertical geophone array clearly demonstrated the development of surface waves as the wave front reached the excavation.

2. The PPV on the skin was 0.7 - to 4.5 -fold greater than in solid rock, depending on the dominant frequency of the event - the lower the corner frequency, the greater the amplification.

3. High frequency seismic events (corner frequencies of $150-200 \mathrm{~Hz}$ ) excited several modes of low frequency vibration $(30-110 \mathrm{~Hz})$, while events with lower corner frequencies $(30-50 \mathrm{~Hz})$ did not always excite the higher modes. This implies that the rock mass around the excavation is a complex medium, and should be studied using a multi-degree-of-freedom model.

4. It was possible to decompose the response into structural and site effects. The structure, i.e. geometry of the excavation, was revealed in the frequency of the coda wave that developed on the skin $(40 \mathrm{~Hz}$ and $60-70 \mathrm{~Hz})$. The site response was revealed in changes in response between closely-spaced geophones. This was attributed to variations in fracturing and the influence of support elements. Attempts made to model the site effect using sine- and rectangular-shaped inclusions predicted unrealistically large dimensions.

\section{3 PPV design criterion for rockburst support}

A PPV of $3 \mathrm{~m} / \mathrm{s}$ has been used as a design criterion for rockburst resistant support in gold mines since the 1980s (Wagner, 1982), while a value of $1 \mathrm{~m} / \mathrm{s}$ has been adopted for platinum mines. Cichowicz (2001) and Milev et al. (2002) investigated whether the PPV at the excavation surface was a useful criterion for the design rockburst support for tunnels and stopes, and if so, what value should be used.

Milev et al. (2002) developed a cheap Peak Velocity Detector (PVD) capable of measuring strong motions of up to $4 \mathrm{~m} / \mathrm{s}$ in stopes, and measured the PPV at 41 sites in Carbon Leader and Ventersdorp Contact Reef stopes. The PPVs of over 22,000 events were measured, and were found to approach, but not exceed, $3 \mathrm{~m} / \mathrm{s}$. This empirical evidence is at variance with McGarr's (2001) arguments that ground velocity should not exceed $1.5 \mathrm{~m} / \mathrm{s}$ in the near-field. The discrepancy may be explained by the fact that mining-induced events are not only caused by slip on weak fault zones, but sometimes by the rupture of intact rock ('Ortlepp shears') that normally form close to the stope. The PVD and mine network data were also used to determine site amplification effects, extending the work of Durrheim et al. (1998a). The site amplification factor was found to:

- decrease with hypocentral distance

- depend on source radius, with a maximum amplification for source radii of 5-30 m

- depend on wavelength, with a maximum amplification for a wavelength of about $30 \mathrm{~m}$, which corresponds to the length of a typical mining panel

- depend on PPV, being greatest for PPV $<100 \mathrm{~mm} / \mathrm{s}$ and small for high PPVs.

A new rockburst support design methodology was proposed that takes into account the buckling, rotation and shearing of keyblocks. The $3 \mathrm{~m} / \mathrm{s}$ PPV criterion was confirmed. A procedure to determine whether a key block was likely to be displaced downward by Rayleigh waves was proposed. If this is indicated, the support 
spacing was adjusted accordingly. However, there was considerable uncertainty regarding some of the parameters in the model.

Cichowicz (2001) investigated the relationship between seismic source parameters, geotechnical parameters of the stope, and the motion of the hanging- and footwall, as well as support units. Accelerometers $(50 \mathrm{~g})$ were placed adjacent to packs in a backfilled stope at Driefontein Mine at two sites $10 \mathrm{~m}$ from the face. In Mponeng Mine the sensors were placed $5 \mathrm{~m}$ from the face, adjacent to and within a $2.3 \mathrm{~m}$ tall brick-composite pack. Seismic events in magnitude range M 1.2-M 2.4 and distance range of $80-140 \mathrm{~m}$ produced PPAs in the range $70-118 \mathrm{~m} / \mathrm{s}^{2}$ and PPVs in the range $0.3-0.5 \mathrm{~m} / \mathrm{s}$. Semi-empirical models were used to determine the PPV-distance relationship. High in-stope PPVs were attributed to near-field effects rather than site effects, as peak values were measured by the horizontal rather than the vertical component. Amplification of ground motion in the stope was observed for three events in magnitude range $M 0.7-M 1.2$, but not for a single $M 2.4$ event. There was no coherence between hangingand footwall motions for (mostly high-frequency) weak ground motion. Cichowicz (2001) recommended that the standard procedure used to calculate energy absorption should be revised because:

- single peak values (e.g. PPA or PPV) are not good predictors of damage as they ignore significant factors such as the frequency and duration of shaking

- only a fraction of the strong ground motion energy imparted to a support unit (brick composite pack) is absorbed through permanent deformation, and most of the energy was returned to the surrounding rock

- seismic events load the rock and support elements cyclically, not monotonically.

Cichowicz (2001) states that no resonance was observed in frequency range $10-100 \mathrm{~Hz}$, hence large events are not amplified. However, this conclusion is based on only five events at a single site. Cichowicz (2001) notes that evidence for $3 \mathrm{~m} / \mathrm{s}$ is purely speculative, but also notes that no large events had been observed in the near field, e.g. $M>2.5$ closer than $50 \mathrm{~m}$.

Cichowicz (2002) extended the work by measuring strong ground motion in the hanging- and footwall and within support units at Mponeng Mine. Several hundred events were recorded by six vertical-component accelerometers. The 26 strongest events were analysed. The strongest recorded ground motion was for a M 1.8 event at a hypocentral distance of $40 \mathrm{~m}$ : the PPA was $170 \mathrm{~m} / \mathrm{s}^{2}$, PPV was $1.2 \mathrm{~m} / \mathrm{s}$, and the final displacement $31 \mathrm{~mm}$. The behaviour of stope support was modelled using a single-degree-of-freedom model with elastic, viscous and plastic components. The response to strong ground motion was found to be radically different to weak ground motion, indicating that simple scaling laws are not applicable. It was concluded that PPA and PPV are inadequate parameters, and that the full waveform should be used, including the rupture time.

\section{4 Summary}

The following characteristics of seismically-induced ground motion that could be relevant for the design of support units and elements, but are not currently taken explicitly into account in the functional specifications for support design, have been identified:

- multi-cyclic nature of ground shaking

- unsynchronised motion between hanging- and footwall

- the possible existence of tensile forces in a hangingwall that is excited by Rayleigh waves.

\section{Observations of rockburst damage in narrow tabular stopes}

Most of the in situ observations described previously were of weak ground motion, and caused no damage to either the hangingwall or to support elements. More than 30 reports of rockburst investigations were reviewed to determine whether there is any credible evidence that the phenomena noted in Section 3.4 
contributed to the ejection of rock or the failure of support elements or systems when subjected to strong ground motion. The principal findings are summarised below. Although many of the investigations took place more than a decade ago (Durrheim et al., 1998a, 1998b), the observations are still believed to be relevant as there have not been any major changes in mining conditions, methods, or support systems in South African mines since then. The annexure contains some examples of these investigations; full reports are contained in Durrheim et al. (1998a).

\subsection{Pre-existing factors that increase the vulnerability of excavations to rockburst damage}

While this study focused on the performance of support during the seismic event, it became apparent that conditions prior to the seismic event often played a very significant role in the distribution and severity of damage. The quality of the rock mass and support elements may deteriorate in long-lived excavations, e.g. tunnels, gullies, thereby increasing the vulnerability of the excavation to strong ground motion. For example; tendons may lose their effectiveness due to corrosion, shear deformation, and repeated seismic loading; the growth of the fracture zone may cause tendons to lose their anchorage in solid rock; and stress redistribution following earlier seismic events may push conditions closer to instability. These gradual changes are not easily detected by visual inspection. Mine officials should be alert for evidence of unusual stress increases and rock deformation, e.g. spalling of sidewalls, unusual deformation of support elements, and decreases in the tunnel section indicative of the growth of the fracture zone.

Many of the rockbursts occurred in areas noted to have higher than average vulnerability because of poor ground conditions, for example, poor hangingwall conditions associated with a dyke or roll in the Ventersdorp Contact Reef, or gaps in backfilling because of operational problems. Either the support standard should cater for the worst-case scenario, or a means to recognise changes in vulnerability and adapt the standards accordingly should be devised. In some instances there were reasons to suspect that support was not fully compliant with standard at the time of the event. It is a perennial challenge to equip and motivate workers to comply with support standards and to monitor work practice.

\section{2 Observations of the co-seismic performance of support}

- Co-seismic convergences of 15 to $30 \mathrm{~cm}$ were estimated based on fresh splits in timber packs and props and the buckling of steel props.

- Ejection velocities: a lower limit of $1.4 \mathrm{~m} / \mathrm{s}$ was estimated based on the tensile failure of a tendon with an attached rock block. Ortlepp (1993) reported ejection velocities as high as $10 \mathrm{~m} / \mathrm{s}$, based on the embedment of rock fragments in insulation pipes, which is far higher than the commonly accepted value for the slip velocity across a fault $(<4 \mathrm{~m} / \mathrm{s})$. The extreme ejection velocities may be explained by the buckling and violent failure of sidewall slabs (McGarr, 1996).

- Punching: several instances of props punching into the hanging- and footwall were noted.

- Performance of yielding props: several instances of failure were observed, either by splitting, buckling or toppling.

- Performance of prop headboards: Some damaged headboards were noted, probably due to a mismatch between the resistance of the yielding prop and the strength of the loadspreader, as well as unevenness of the hangingwall. This damage could have occurred during both aseismic and co-seismic stope closure. In both cases, damage to the headboard would degrade the loadspreading capacity of the prop and could cause damage to the hangingwall.

- Gully packs: Some failures of gully packs were noted. The main failure modes were ejection into the gully, toppling of tall packs, and footwall damage.

- Gully tendons: Many instances of 'naked tendons' were noted in gullies. The tendons were still rooted in the hangingwall, but the surrounded rock mass had unravelled (see Figure 4). 

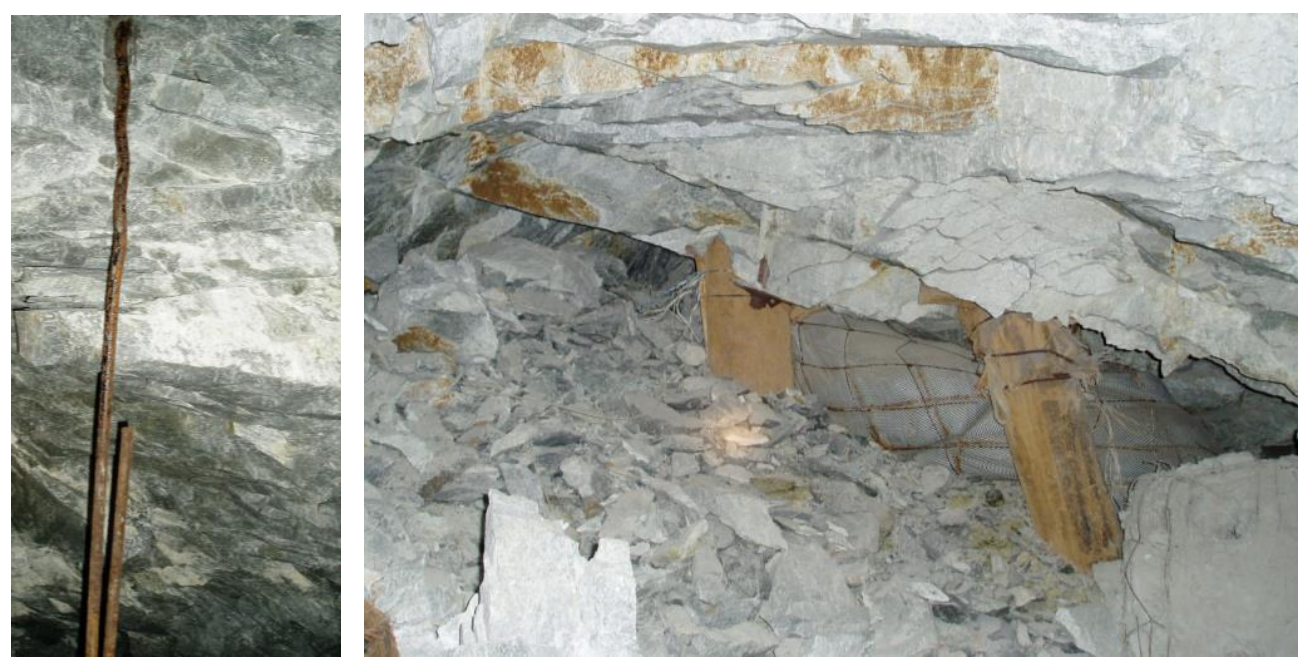

Figure 4 Observations of damage (left) naked tendons ( $r$ ight) punching of props

- Areal coverage: Relatively few instances of the failure of individual support elements were noted. The biggest problem was the ejection of the fractured rock mass between support elements. In some instances the rock mass was probably already fragmented prior to the seismic event (e.g. ubiquitous weak joints), while in other instances the fragmentation of the hangingwall appears to have been co-seismic (e.g. punching of props, tensile failure of an unconfined hangingwall beam).

- Co-seismic transformation of hangingwall properties: In some cases it appeared that the hangingwall quality had changed from apparently stable to unstable during the seismic event. It is postulated that this change occurred virtually instantaneously when stored elastic energy was released and/or the rock mass was shaken violently, breaking the cohesion along joints and bedding planes, or shattering an intact beam. The situation was exacerbated if the beam was intersected by weak joints or was unconfined, e.g. a brow that is not horizontally confined.

- System design: In some cases of tunnel damage it was clear that failure at the weakest or most vulnerable point had cascaded, e.g. a corroded tendon had snapped casting additional load on adjacent elements, mesh had been severed by tendon base plates. Similar situations are likely to arise in stopes.

\section{1 Multi-cyclic shaking}

Seismograms, especially of larger events, rarely display a single displacement pulse. Several phenomena contribute to the complexity of the ground motion: extended seismic sources comprising several asperities, as well as path and site effects. In-stope measurements have frequently identified co-seismic closure of several centimetres. For example, Milev et al. (2002) measured co-seismic stope closure of $10 \mathrm{~cm}$ more than $100 \mathrm{~m}$ from the focus of a M 2.7 event. The sampling rate of the closure metre was too slow to capture the actual displacement history. However, the seismogram showed several cycles of ground motion, and it is considered unlikely that the in-stope displacement was achieved in a single stroke.

A mismatch between the yield and elasticity of the support element and the motion of the stope surface could produce a 'hammering' effect (which may explain the occasional penetration of support units into the 'solid' roof or floor) and cause damage to the hangingwall that could trigger co-seismic unravelling or subsequent instability. It is also conceivable that a prop could topple while it is not in contact with the roof and floor.

Implications for support specifications: The support element should be able to yield on the downstroke, but have sufficient elastic resilience to maintain contact with the hangingwall on an upstroke of several 
centimetres. As the shaking is likely to be in the $5-50 \mathrm{~Hz}$ frequency band, the unit should be able to react within say, 10 milliseconds. The use of load-spreading head and footboards should reduce the amount of damage done to the rock and limit the penetration. An alternative approach is to replace or supplement props with tendons and faceplates with appropriate elastic and ductile properties. It should be noted that the installation of tendons long enough to be anchored in solid rock in stopes that are often only $1.2 \mathrm{~m}$ high presents major operational challenges.

\section{2 Unsynchronised motion between hanging- and footwall}

Not only is ground motion multi-cyclic, but the hanging- and footwall motions may have different directions, amplitudes and phases. To keep the analysis simple, we considered motion perpendicular and parallel to the stope plane. For example, the footwall moving down while the hangingwall moved up, and vice versa. This motion would exacerbate the hammering described above. In extreme cases, unsynchronised motion parallel to the stope could result in shear motion and toppling of props. The ground displacements produced by body and surface waves in the far-field are likely to be of the order of millimetres to centimetres, insufficient to cause props to topple. However, other scenarios arise in the near-field that could give rise to a ride of 10 s of centimetres, e.g. a fault plane that intersects the stope, or movement along a bedding plane.

Implications for support specifications: In earthquake engineering, cross-bracing and/or shear walls are used to resist shear motion of the structural members. However, the cross-braces only have the mass of the building to contend with. It is difficult to conceive of a practical support system that would be able to resist near-field shear motion in a mine, where the motion of a huge mass of rock is involved. The best option may be to design a support unit that can survive shear motion of say, $15^{\circ}$ from the vertical (equivalent to ride of $50 \mathrm{~cm}$ in a $2 \mathrm{~m}$ stope) while continuing to provide support to the hangingwall. This could be achieved, for example, by hinged headboards that are able to withstand some rotation.

\section{3 Tensile forces in a hangingwall excited by Rayleigh waves}

While it remains to be proven that the dilatational phase of a Rayleigh wave is sufficiently strong to nullify the compressional clamping forces and actually produce tensile forces, it is likely that the compressional forces are briefly reduced during shaking. The momentum of a key block bounded by unfavourably orientated fractures could cause it to slip slightly downwards during each cycle until it falls, possibly causing the hangingwall to unravel. This could account for 'falls of ground associated with a seismic event', often quite distant from the focus. Blocks most vulnerable to this form of ejection would seem to be relatively thin slabs bounded on the upper side by a weak bedding plane (Figure 5).

Implications for support specifications: Active areal support is required to prevent unravelling of the hangingwall, e.g. $200 \mathrm{~kg}$ resistance to be applied at a spacing not to exceed $50 \mathrm{~cm}$ (sufficient to support a slab with dimensions $50 \times 50 \times 20 \mathrm{~cm}^{3}$, density $2500 \mathrm{~kg} / \mathrm{m}^{3}$, mass $125 \mathrm{~kg}$ ).
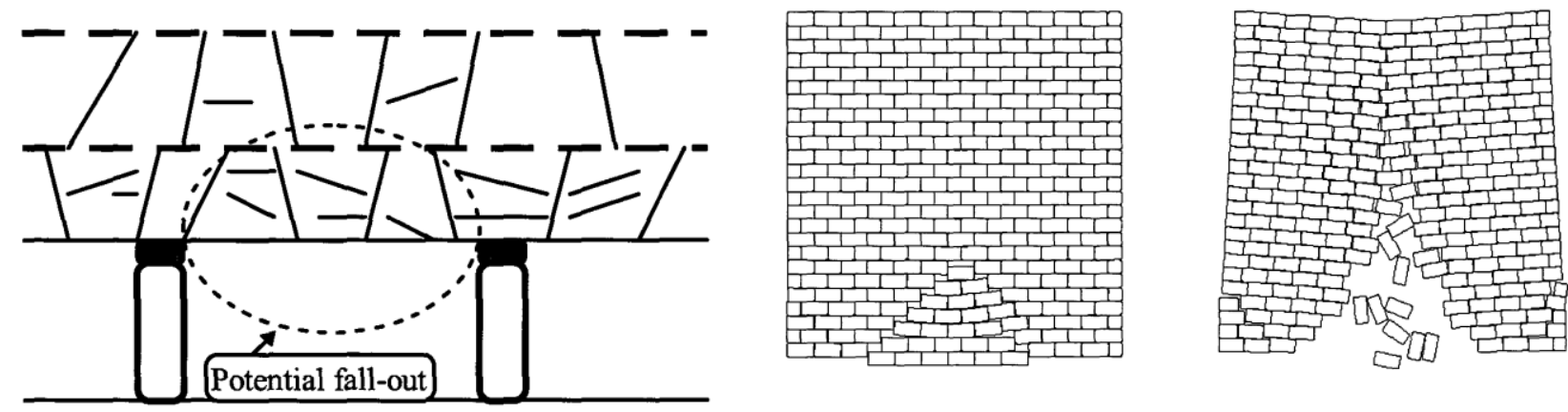

Figure 5 Diagram comparing potential hang ingwall shake-down with the unravelling of unreinforced masonry 


\section{4 Practical considerations}

The functional specifications used in the development of the $3 \mathrm{~m} / \mathrm{s}$ rapid-yielding hydraulic prop (RYHP) with loadspreader (Taggart and Hojem, 1992) were used as the starting point in this review. In many respects this seems to meet the performance requirements for dynamic loading as well, if not better, than many of the newer props. Yet the RYHP has fallen out favour for many mines (Glisson and Kullmann, 1998). The main reason for this is that the rows of RYHPs are cycled forward as the face advances, involving a significant cost and management burden, as well as some risk of injury when removing props. In contrast, elongates are never removed. Ideally, for any new element or system to be adopted, it should deliver superior performance without extra cost, effort or risk.

\section{Conclusion}

A review of seismic theory and observations and rockburst damage investigations has identified several characteristics of seismically-induced ground motion that are not taken explicitly into account in the functional specifications for support design, i.e. multi-cyclic shaking, shear motion between hanging- and footwall, transient tensile forces, and structural resonances. While we agree with Stacey (2011) that there is much to learn about the demand imposed on support by seismic events and the performance capacity of support systems under dynamic loading, we do not believe that the only option is to accept design indeterminacy and adopt a conservative specification approach.

Firstly, we believe that there is scope to improve our knowledge of the dynamic response of the hangingwall and the stope. A project initiated in 2010, 'Observational studies to mitigate seismic risk in mines' (Durrheim et al., 2010; 2012), seeks to do just this. While it is likely that dynamic phenomena are highly variable, it may be possible to constrain certain parameters. Secondly, we believe that there is scope to improve support performance through innovations that are better attuned to actual ground motion. In this paper we have proposed functional specifications, and challenge innovative engineers to design support elements and systems that meet (or beat) the criteria. It is possible that this may be achieved by quite simple modifications to current technologies. For example, during the investigation into the risks posed by large seismic events in the gold mining areas (Durrheim et al., 2007), Robert Anderson of the Californian Seismic Safety Commission indentified very simple and cheap modifications to structures that could reduce losses, e.g. strapping hot water heaters to the roof trusses, stabilising water towers with cables. Thirdly, support capacities can be better quantified by testing support elements and systems under conditions that simulate the actual ground motion more closely by using facilities similar to those used by earthquake engineers. Fourthly, we can continue to carefully document and interpret damage to the rock and support elements and systems. Finally, we can use the results of underground observations and laboratory tests to calibrate numerical simulations.

Ultimately the best way to reduce rockburst risk is to avoid exposure in areas with a high hazard, but it will take a revolution in mining technology to remove workers from the deep stopes in South African gold and platinum mines. In the meantime, we should seek to reduce risk by making the working places rockburst resistant.

\section{Acknow l edgements}

The contributions of the members of the Gold Fields Seismic Task Team are acknowledged: George Ashworth, Van Zyl Brink, Frans Castelyn, Riccardo Ferreira, Francois Malan, Kevin Riemer, Mike Roberts, Ephraim Sibanda and Steve Spottiswoode. Gold Fields Ltd is thanked for permission to publish the work.

\section{References}

Bozorgnia, Y. and Bertero, V. (2004) Earthquake Engineering: from Engineering Seismology to Performance-based Engineering, CRC Press.

Cichowicz, A. (2001) The meaningful use of peak particle velocity at excavation surface for the optimisation of the rockburst support criteria for tunnels and stopes, Final report GAP709b (unpublished), Mine Health and Safety Council, Johannesburg. 
Cichowicz, A. (2002) Interaction between stope support and ground motion in the hangingwall and footwall, Final report GAP7845 (unpublished), Mine Health and Safety Council, Johannesburg.

Cichowicz, A., Milev, A.M. and Durrheim, R.J. (1999) Transfer function for a seismic signal recorded in solid rock and on the skin of an excavation, Journal of the SIAMM, Vol. 99, pp. 201-206.

Durrheim, R.J., Anderson, R.L., Cichowicz, A., Ebrahim-Trollope, R., Hubert, G., Kijko, A., McGarr, A., Ortlepp, W.D. and Van der Merwe, N. (2007) The Risks to Miners, Mines and the Public Posed by Large Seismic Events in the Gold Mining Districts of South Africa, in Proceedings Fourth International Seminar on Deep and High Stress Mining, Y. Potvin (ed), 7-9 November 2007, Perth, Australia, Australian Centre for Geomechanics, Perth, Chapter 4, pp. 33-40.

Durrheim, R.J., Kullmann, D.H., Stewart, R.D. and Cichowicz, A. (1996) Seismic excitation of the rock mass surrounding an excavation in highly stressed ground, in Proceedings 2nd North American Rock Mechanics Symposium, M. Aubertin, F. Hassani and H. Mitri (eds), pp. 389-394.

Durrheim, R.J., Milev, A., Spottiswoode, S.M. and Vakalisa, B. (1998a) Improvement of worker safety through the investigation of the site response to rockbursts, Final report GAP201 (unpublished), Mine Health and Safety Council, Johannesburg.

Durrheim, R.J., Ogasawara, H., Nakatani, M., Yabe, Y., Kawakata, H., Naoi, M., Ward, A.K., Murphy, S.K., Wienand, J., Lenegan, P. Milev, A.M., Murakami, O., Yoshimitsu, N., Kgarume, T., Cichowicz, A., and the JST-JICA SA research group (2012) Establishment of SATREPS experimental sites in South African gold mines to monitor phenomena associated with earthquake nucleation and rupture, in Proceedings Sixth International Seminar on Deep and High Stress Mining, Y. Potvin (ed), 28-30 March 2012, Perth, Australia, Australian Centre for Geomechanics, Perth, pp. 173-188.

Durrheim, R.J., Ogasawara, H., Nakatani, M., Yabe, Y., Milev, A., Cichowicz, A., Kawakata, H., Moriya, H. and the JST-JICA SA research group (2010) Observational Study to Mitigate Seismic Risks in Mines: a new Japanese-South African collaborative project, in Proceedings Fifth International Seminar on Deep and High Stress Mining, M. Van Sint Jan and Y. Potvin (eds), 6-8 October 2010, Santiago, Chile, Australian Centre for Geomechanics, Perth, pp. 215-225.

Durrheim, R.J., Roberts, M.K.C., Haile, A.T., Hagan, T.O., Jager, A.J., Handley, M.F. and Spottiswoode, S.M. (1998b) Factors influencing the severity of rockburst damage in South African gold mines, Journal of the South African Institute of Mining and Metallurgy, Vol. 98, pp. 53-57.

Glisson, F.J. and Kullmann, D. (1998) Problems associated with the use of Rapid yielding Hydraulic Props, Final report GAP330 and GAP442 (unpublished), Mine Health and Safety Council, Johannesburg.

Hagan, T.O., Milev, A.M., Spottiswoode, S.M., Vakalisa, B. and Reddy, N. (1999) Improvement of worker safety through the investigation of the site response to rockbursts (Continuation of GAP 201), Final report GAP530 (unpublished), Mine Health and Safety Council, Johannesburg.

Heal, D. and Potvin, Y. (2007) In situ dynamic testing of ground support using simulated rockbursts, in Proceedings Fourth International Seminar on Deep and High Stress Mining, Y. Potvin (ed), 7-9 November 2007, Perth, Australia, Australian Centre for Geomechanics, Perth, pp. 373-394.

Jager, A.J. and Ryder, J.A. (eds) (1999) A Handbook on Rock Engineering Practice for Tabular Hard Rock Mines, The Safety in Mines Research Advisory Council, Johannesburg, $371 \mathrm{p}$.

Linkov, A. and Durrheim, R.J. (1998) Velocity amplification considered as a phenomenon of elastic energy release due to softening, in Proceedings Third International Conference on Mechanics of Jointed and Faulted Rocks, H.P. Rossmanith (ed), 6-9 April 1998, Vienna, Austria, A.A. Balkema, Rotterdam, pp. 243-248.

McGarr, A. (1996) A mechanism for high wall-rock velocities in rockbursts, Workshop on Induced Seismicity, North American Rock Mechanics Symposium, 18 June 1996, Montreal, Canada.

McGarr, A. (2001) Control of strong ground motion of mining-induced earthquakes by the strength of the seismogenic rock, in Proceedings of the Fifth International Symposium on Rockbursts and Seismicity in Mines, G. van Aswegen, R.J. Durrheim and W.D. Ortlepp (eds), SAIMM, Johannesburg, pp. 69-74.

Milev, A.M., Spottiswoode, S.M., Noble, B.R., Linzer, L.M., Van Zyl, M., Daehnke, A. and Acheampong, E. (2002) The meaningful use of peak particle velocity at excavation surface for the optimisation of the rockburst support criteria for tunnels and stopes, Final report GAP709a (unpublished), Mine Health and Safety Council, Johannesburg.

Milev, A.M., Spottiswoode, S.M., Rorke, A.J. and Finnie, G.J. (2001) Seismic monitoring of a simulated rockburst on a wall of an underground tunnel, Journal of the South African Institute of Mining and Metallurgy, Vol. 101, pp. 253-260.

Ortlepp, W.O. (1993) High ground displacement velocities associated with rockburst damage, in Proceedings of the Third International Symposium on Rockbursts and Seismicity in Mines, P. Young (ed), Rotterdam, Balkema, pp. 101-106.

Stacey, T.R. (2009) The importance of engineering design with regard to safety in mining, Hard Rock Safe Safety Conference, South African Institute of Mining and Metallurgy.

Stacey, T.R. (2011) Support of excavations subjected to dynamic (rockburst) loading, in Harmonising Rock Engineering and the Environment, in Proceedings of the 12th ISRM International Congress on Rock Mechanics, Beijing, China, 18-21 October 2011, Q. Qian and Y. Zhou (eds), CRC Press, London, pp. 137-145.

Taggart, P.N. and Hojem, J.P.M. (1992) Development of load spreaders for use with hydraulic prop based support systems, Chamber of Mines Research Organisation, Report number RR 92-014 (unpublished), Chamber of Mines of South Africa.

Vieira, F.M.C.C., Diering, D.H. and Durrheim, R.J. (2001) Methods to mine the ultra-deep tabular gold-bearing reefs of the Witwatersrand Basin, South Africa, Underground Mining Methods: Engineering Fundamentals and International Case Studies, W.A. Hustrulid and R.L. Bullock (eds), Society for Mining, Metallurgy, and Exploration, Inc., pp. 691-704.

Wagner, H. (1982) Support requirements for rockburst conditions, in Proceedings of the First International Symposium on Rockbursts and Seismicity in Mines, N. Gay and E.H. Wainwright (eds), South African Institute of Mining and Metallurgy Symposium Series No. 6 (1984), pp. 209-218. 


\section{Annexure - Summary of selected investigations into rockbursts}

Abbreviations: f/w - footwall; h/w - hangingwall; $M$ - local magnitude; RHYP - Rapid-yielding hydraulic prop; VCR - Ventersdorp Contact Reef

Date:

10 January 1994

District and reef:

Far West Rand, Ventersdorp Contact Reef

Mining scenario:

Extraction of island remnant at a depth of $1,840 \mathrm{~m}$

Local magnitude:

M 2.6 followed within $30 \mathrm{~s}$ by M 1.9 event. Events were external to the seismic network; hence the location accuracy was poor.

Source mechanism:

Failure of parts of remnant where width was less than $11 \mathrm{~m}$.

Damage mechanism: Strike gully was supported by prestressed composite packs. Co-seismic closure up to $80 \mathrm{~cm}$, packs punch into f/w. Stope supported by composite packs and $400 \mathrm{kN}$ RYHPs with $300 \mathrm{~mm}$ load spreaders. Evidence for co-seismic closure of $15 \mathrm{~cm}$. Face ejections and shake-down of fragmented h/w beam to $80 \mathrm{~cm}$ was observed.

Support performance: Support system rendered ineffective due to co-seismic fragmentation of hard lava $\mathrm{h} / \mathrm{w}$. The use of $800 \mathrm{~mm}$ load spreaders was recommended.

Date:

4 May 1994

District and reef:

Far West Rand, Ventersdorp Contact Reef

Mining scenario:

Local magnitude:

Extraction of peninsular remnant at depth of 2,300 m

Source mechanism:

M 2.1, located within the remnant.

Damage mechanism: Stope supported by $1.1 \times 1.1 \mathrm{~m}$ composite packs and RYHPs with headboards. A trench had been dug to negotiate a roll in the reef, and mining continued under the brow. However, the brow had not been confined and contained many weak joints in the hard lava h/w. Co-seismic convergence estimated at 50-150 mm. H/w fragmented co-seismically. North-eastern face of remnant ejected into the stope without damage to $\mathrm{h} / \mathrm{w}$.

Support performance: Support deemed to be ineffective due to fragmentation of h/w. Brows should be confined. The use of larger headboards was recommended.

Date:

District and reef:

Mining scenario:

Local magnitude:

Source mechanism:

Damage mechanism:

\section{Support performance:}

3 November 1994

Far West Rand, Carbon Leader

Longwall negotiating dyke at 3,000 m

M 2.5, event located 50-100 m from the damaged panel.

Slip on dyke.

Faceburst and shakedown of $1 \mathrm{~m} \mathrm{~h} / \mathrm{w}$ beam. Convergence about $10 \mathrm{~cm}$. Numerous joints and fractures in $\mathrm{h} / \mathrm{w}$. Stope supported by backfill within $3.5 \mathrm{~m}$ of the face (bags supported by pipe sticks) and single row of $400 \mathrm{kN} 1 \mathrm{~m} / \mathrm{s}$ RYHPs without headboards. Packs were installed in the area of the dyke intersection.

Twenty-eight $40 \mathrm{t}$ RYHPs props were recovered and tested. Seven were non-functional, although the condition at the time of the burst could not be determined. The other 21 props survived a $1 \mathrm{~m} / \mathrm{s}$ test, though with considerable variation in energy absorption. Props that punched into the $\mathrm{h} / \mathrm{w}$ did not exhibit unusual stiffness. The amount of available travel at the time of the burst could not be determined. $\mathrm{H} / \mathrm{w}$ collapse was attributed to fragmentation of $\mathrm{h} / \mathrm{w}$ owing to poor ground conditions and single row of props supporting $3.5 \mathrm{~m}$ face-backfill span. Two rows of RYHP with headboards were recommended. 
Date:

District and reef:

Mining scenario:

Local magnitude:

Damage mechanism:

Support performance:
Source mechanism:

4 July 1995

Klerksdorp, Vaal Reef

Extraction of final remnants near shaft at 2,220 m

M 3.4.

Slip on fault.

Bulking of haulage sidewall over $60 \mathrm{~m}$. Failure of rebar, mesh and lacing support.

Tunnel supported by $3 \mathrm{~m} \times 16 \mathrm{~mm}$ shepherds crook smooth bar on a $1 \times 1 \mathrm{~m}$ pattern with $100 \mathrm{~mm}$ weld mesh and $10 \mathrm{~mm}$ lacing. Rebars were considered to be sufficiently long to be anchored in stable rock mass. Shearing and debonding of some rebars (but not shear failure) attributed to pre-seismic deformation, as well as an instance of tensile failure of a rebar was observed. Failure of system under severe loading attributed to deterioration of rebar bounds in the fractured envelope increasing the load on the mesh and lacing leading to failure at the points where the soft fabric was connected to the stiff rebars.

Date:

18 September 1995

District and reef:

Mining scenario:

Local magnitude:

Source mechanism:

Damage mechanism:

Support performance:

Far West Rand, Ventersdorp Contact Reef

Mining of remnant between longwalls at depth of 2,200 m

M 2.2.

Slip on face parallel rupture.

Shakedown of the hangingwall in the face area and in the wide heading about $30 \mathrm{~m}$ from the focus of the tremor.

The face area was supported by two rows of RYHPs; the back area by $1.1 \times 1.1 \mathrm{~m}$ prestressed solid timber mat packs spaced $1.5 \mathrm{~m}$ skin-to-skin on dip and strike; and the wide heading by fully grouted $2.2 \mathrm{~m}$ ripple bars, in rows $1.5 \mathrm{~m}$ apart. Lava h/w had blocky structure owing to interaction of vertical face-parallel fractures and subhorizontal flow surfaces. Damage confined to face areas where the distance between the face and support unit exceeded $2 \mathrm{~m}$. The fallout height was 1-3 $\mathrm{m}$. Fresh splitting of packs indicated co-seismic convergence in back area of $100 \mathrm{~mm}$, though there was little or no fall out between packs. In the wide heading it appeared that the distance from the face to the first line of support was about $4 \mathrm{~m}$. The critical factor appeared to be unsupported spans exceeding $2 \mathrm{~m}$.

Date:

District and reef:

Mining scenario:

Local magnitude:

Source mechanism: Damage mechanism: Support performance:
30 January 1996

Far West Rand, Carbon Leader

Extraction of stabilising pillar at depth of $1,900 \mathrm{~m}$ using face-parallel preconditioning

M 2.2 and $M 2.3$ within $1 \mathrm{~s}$. The closest event was within $20 \mathrm{~m}$ of the mining panel, and $15 \mathrm{~m}$ in the $\mathrm{h} / \mathrm{w}$. The second event was some $100 \mathrm{~m}$ away.

Pillar failure.

Shakedown of strike gully $\mathrm{h} / \mathrm{w}$.

The immediate $\mathrm{h} / \mathrm{w}$ consisted of a laminated quartzite (about $1 \mathrm{~m}$ ) with a $2 \mathrm{~m}$ shale band above. The gully h/w was fragmented by steeply dipping shear zones associated with ancient tectonism, fractures parallel to the pillar axis related to past mining, and fractures normal to the pillar axis related to current mining. Panel support consisted of timber packs installed within $2 \mathrm{~m}$ of the face, spaced $1.5 \mathrm{~m}$ skin-to-skin. Co-seismic convergence in the panels ranged from $50-140 \mathrm{~mm}$. A Ground Motion Monitor in the stope recorded $\mathrm{a}_{\max }=4.2 \mathrm{~g}$ and $\mathrm{v}_{\max }=470 \mathrm{~mm} / \mathrm{s}$, considerably less than the values recorded during preconditioning blasts that cause no damage. However, the strong shaking had duration of $80 \mathrm{~ms}$. Only minor 
falls of ground had occurred between the face and first row of packs. The gully shoulders were supported by solid timber packs, spaced $1.5 \mathrm{~m}$ skin-to-skin. The stoping height was $1 \mathrm{~m}$, although the gully packs were sometimes considerably taller owing to past fall outs. Occasional split set tendons were installed in the $\mathrm{h} / \mathrm{w}$. Three substantial falls of ground had occurred in the strike gully, with fall-out heights of about $3 \mathrm{~m}$. The gully support did not cater for the highly fragmented nature of the $\mathrm{h} / \mathrm{w}$. At the very least long $(8 \mathrm{~m})$ tendons capable of surviving shearing combined with straps or mesh and lace would have been required. The effort to extract the pillar was abandoned.

Date:

District and reef:

Mining scenario:

Local magnitude:

Source mechanism:

Damage mechanism:

Support performance:
18 November 1996

Far West Rand, Carbon Leader

Mining a longwall at a depth of 3,300 $\mathrm{m}$ through a $10 \mathrm{~m}$ wide dyke.

M 3.0, event located within 50 m of working places.

Slip on dyke.

Severe damage to strike gullies and minor falls of ground in the face area. There was evidence for co-seismic closure of $200-300 \mathrm{~mm}$ in the panels. Fall-out extended for some $60 \mathrm{~m}$ in the $2 \mathrm{~m}$ wide gully, with most fall-outs about $1.8 \mathrm{~m}$ high, but some as high as $4 \mathrm{~m}$.

Stope support consisted of pre-stressed timber elongates and backfill, with timber packs lining the gullies. No tendons were installed in the gullies. Mechanical props were used for temporary support. Panels protected by backfill and elongates only suffered minor damage, though about 30 per cent of the props had failed, mostly by tilting of the headboards, and had lost their capacity to absorb any further energy. The most serious shortcoming was the lack of areal coverage in the gullies.

Date:

District and reef:

Mining scenario:

Local magnitude:

Source mechanism:

Damage mechanism:

7 May 1997

Far West Rand, Ventersdorp Contact Reef

Mining of longwall at depth of 2,700 m

M 3.4, event located within 50 m of working places.

Slip on fault. Several faults are present in the area, which had a history of unusually high seismicity.

Damage included face ejection, and shakedown of the stope hangingwall where face to support distances exceeded $3 \mathrm{~m}$. The fall-out heights were up to $1 \mathrm{~m}$. There was evidence of co-seismic closure of $150 \mathrm{~mm}$. Damage was most severe in the vicinity of the reef-crosscut intersection where the sidewall had been violently ejected into the haulage.

Support performance: Mining-induced fractures were prominent. Permanent stope support consisted either of timber packs or steel elongates and backfill. Mechanical props were used for temporary support. While the steel elongates had generally performed well, some headboards were severely distorted and some steel barrels had been split. 
